\title{
Casting Aluminum Fatigue Assessment Correction Method Based on Crack Propagation Prediction
}

\author{
LI Guodong1,ab WANG Xingyu'2,b ZENG J ing 3 3,a
}

a State Key Laboratory of Traction Power, S outhwest J iaotong University, Chengdu 610031,China;

b CRRC Chang Chun Railway Vehicles CO, .LTD, Chang Chun 130062, China

a maklcewxy@163.com, b wangxingyu@ cccar.com.cn

\section{Keywords: Casting Aluminum; Crack Propagation; Fatigue Assessment; Prediction}

\begin{abstract}
The fatigue requirement of casting aluminum alloy is varied for different industry, however, it is hard to avoid porosity, shrinkage, or slag during the casting process, leading to uneven quality of casting. the fatigue strength will be influenced by casting porosity, DAS length or stress level. This paper takes single reduction gearbox housing (material for $\mathrm{AlSi}_{7} \mathrm{Mg}_{0.3}$ ) as an example to analyze the prediction algorithm of crack propagation, deduce the key parameters for deciding crack propagation, and carry out a series of experimental studies for casting aluminum fatigue. According to the results of calculation and experiment, the correction coefficient is introduced based on FKM guideline and EN 1999 standard, besides, the evaluation method of fatigue strength has been corrected. As one example, the test results show that if casting aperture diameter more than $0.5 \mathrm{~mm}$, the stress amplitude of fatigue load should not be more than $38.28 \mathrm{MPa}$ for $1 \times 10^{7}$ load cycles.
\end{abstract}

\section{Introduction}

Since the casting aluminum alloy has many advantages, such as small density, high strength, corrosion resistant and easy to shape, it can be widely used in aviation, railway, automobile and other industrial fields. With the improvement of alloy smelting process, the performance of aluminum alloy has been improved continually. The mechanical properties, low temperature performance and wear resistance performance have been full played. However, in view of different needs of different industries, the fatigue requirements of casting aluminum alloy are quite different, due to the casting process is hard to avoid porosity, shrinkage or slag, that often cause uneven casting quality although evaluate fatigue limitation base on the same requirements. By contrast, the real life is very different, which will impact fatigue limit including low cycle and high cycle ${ }^{[1-5]}$. How to accurately assess the fatigue limit according to the level of casting defects is mainly study content in this article. The FKM guideline did not elaborate the numerical relationship between aperture diameter and fatigue limitation, the parameters such as $j_{G}$ and $j_{F}$ need to be adjust appropriately, besides, despite EN1999 standard(Eurocode9:Design of aluminum structures) stipulated the relationship between the aperture diameter levels and the fatigue limitation, but the $10^{7}$ times cycles corresponding to the fatigue limitation was not clearly given.

This article takes the single reduction gearbox housing of China high-speed EMU as example(the housing material is $\mathrm{AlSi}_{7} \mathrm{Mg}_{0.3}$ ), in view of this type housing existed a batch of cracks, it is necessary to carry out evaluation method research comprehensively, therefore, a series of experimental studies for casting aluminum fatigue have been made, and the predicting methods of casting aluminum crack propagation has also been introduced. 
According to the calculation and test results, the fatigue correction coefficients have been forwarded, the fatigue evaluation methods have been amended, the recommended value of fatigue limit for $\mathrm{AlSi}_{7} \mathrm{Mg}_{0.3}$ casting aluminum alloy has been introduced.

\section{Problem Statements}

As an example, the $\mathrm{AlSi}_{7} \mathrm{Mg}_{0.3}$ housing crack fault is shown in figure1, according to fracture analysis, there are obvious fatigue striations, as shown in figure2, according to metallographic analysis, the fracture reason belongs to fatigue crack. Once the crack occurred, the fatigue striations will be the results of high stress intensity. However, due to casting quality and evaluation approach will take a great influence on prospective life of $\mathrm{AlSi}_{7} \mathrm{Mg}_{0.3}$ housing, therefore, it is necessary to re-determine fatigue assessment thresholds for housing crack problems.

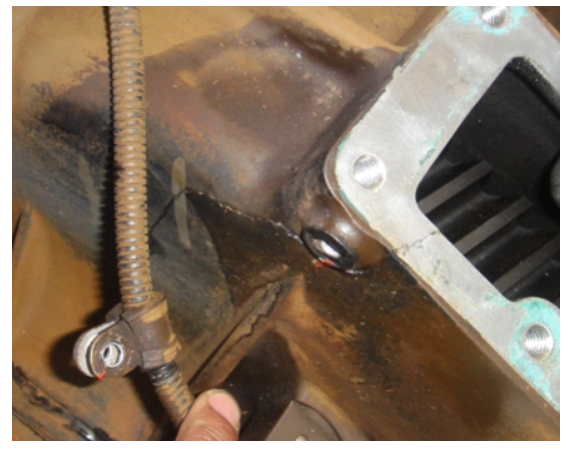

Fig1. Crack fault of gearbox housing

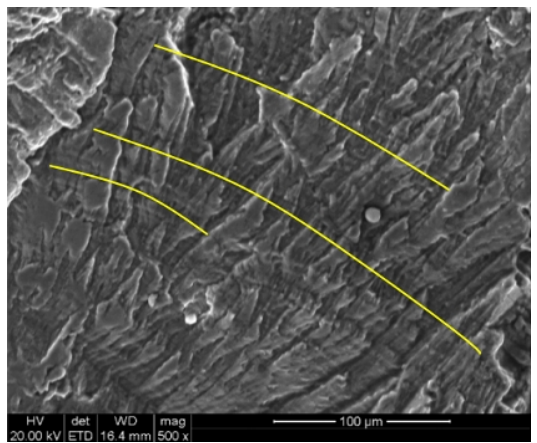

Fig2. Fatigue striations of housing fracture

\section{Prediction method of crack extension}

The stress method and strain gauge method have been widely used to predict fatigue life in engineering field, for some complicated structure or complex stress, using the two methods to predict fatigue life is inaccurate. In the early stages of crack extension, the crack tendency T- in the region of total product extension. In this paper, the crack extension life is determined by the crack propagation life. Assume that the $\mathrm{AlSi}_{7} \mathrm{Mg}_{0.3}$ materials is elastic solid, a-Al-matrix is elastoplasticity, the $\mathrm{Si}$ is rigid elastic solid, the Young's modulus and Poisson's ratio are shown in Table 1.

Table1.Property parameter of $\mathrm{AlSi}_{7} \mathrm{Mg}_{0.3}$ material

\begin{tabular}{ccc}
\hline Material & Young modulus $(\mathrm{GPa})$ & Poisson ratio \\
\hline $\mathrm{AlSi}_{7} \mathrm{Mg}_{0.3}$ & 70 & 0.3 \\
\hline a-Al-matrix & 6089 & 0.33 \\
\hline Si grain & 130 & 0.28
\end{tabular}

Life Equation of crack formation according to the aluminum alloy material as Equation (1) ${ }^{[6-10]}$ :

$$
N_{i}=\frac{C_{0}}{\lambda_{2}}\left[\frac{1}{\sigma_{a}}\left(k_{0}+\frac{\alpha}{\sqrt{\lambda_{2}}}\right)\right]^{\frac{2}{\beta}}
$$

In Equation (1):

$\lambda_{2}$-The length of dendrite arm spacing (DAS);

$\sigma_{a}$-stress amplitude;

$\beta$-Constant of material properties;

$C_{0}, k_{0}, \alpha$-Constants determined by material properties.

The crack propagation prediction formula as Equation (2). 


$$
\frac{d L}{d N}=C\left[\left(\varepsilon_{\max } \frac{\sigma_{a}}{\sigma_{Y}}\right)^{-s} L\right]^{t}
$$

In Equation (2):

$L$ - Crack length;

$\varepsilon_{\max }$ - The maximum strain of cyclic load;

$\sigma_{Y}$ - Yield stress of material;

$s, t, C$ - Constants;

$L_{0}$-The initial crack length;

$L_{f}$-The finial crack length;

Under the same loading condition, increase yield stress will reduce speed of crack propagation, because increasing material yield strength is beneficial to reduce the amount and area of plastic deformation in the interior of materials, as results, the displacement reduction among crystal particles in crystallographic orientation region, the possibility of fatigue crack on the crack tips will be reduced. Using the initial crack length $L_{0}$ and final crack length $L_{f}$ to instead of $L$ in Equation (2), it will be translated into Equation (3).

$$
N_{p}=\frac{d L}{d N}=C_{1}\left(\varepsilon_{\max } \frac{\sigma_{a}}{\sigma_{Y}}\right)^{-s \times t}\left(L_{0}^{-t+1}-L_{f}^{-t+1}\right)
$$

Assume that the initial crack length $L_{0}$ is equal to $2 \lambda_{2}$. In order to find the overall fatigue life, the crack initiation life and crack propagation life have been added, as Equation (4):

$$
N_{f}=N_{p}+N_{i}=\frac{C_{0}}{\lambda_{2}} \cdot\left[\frac{1}{\sigma_{a}}\left(k_{0}+\frac{\alpha}{\sqrt{\lambda_{2}}}\right)\right]^{\frac{2}{\beta}}+C_{1}\left(\varepsilon_{\max } \frac{\sigma_{a}}{\sigma_{Y}}\right)^{-s \times t} \cdot\left(L_{i}^{-t+1}-L_{f}^{-t+1}\right)
$$

The fatigue life of housing is mainly affected by pores (shrinkage), DAS length and stress level, according to the specification of gearbox, the fatigue life of housing needs to reach $10^{7}$ loading cycles, combine the data of housing fatigue testing, the crack propagation life $N_{p}$ is greater than the initial crack formation life $N_{i}$, Equation (4) is approximate to Equation (5):

$$
N_{f} \approx N_{p}=C_{1}\left(\varepsilon_{\max } \frac{\sigma_{a}}{\sigma_{Y}}\right)^{-s \times t}\left(L_{0}^{-t+1}-L_{f}^{-t+1}\right)
$$

Assume the $L_{0}$ can be expressed by equivalent pore diameter of crack formation(assume $\left.L_{0}=0.5 \mathrm{~mm}\right)$, and the final fatigue failure length $L_{f}=5 \mathrm{~mm}$, set constant : $C=1.04 \times 10^{-5}, s=1.05$, $t=1.94, \varepsilon_{\max }$ and $\sigma_{a}$ are abbreviated to $\varepsilon_{\max }=\frac{\sigma_{\max }}{E}$ and $\sigma_{a}=\left(\frac{1-R}{2}\right) \sigma_{\max }$ respectively, $\mathrm{E}$ is young's modulus of $\mathrm{AlSi}_{7} \mathrm{Mg}_{0.3}$ in condition $\mathrm{T} 6, \sigma_{Y}$ is material yield strength $\mathrm{AlSi}_{7} \mathrm{Mg}_{0.3}$ in condition T6, set $E=70 G P a$, set $\sigma_{Y}=190 M P a . \sigma_{\max }$ and $R$ represent the maximum stress and maximum stress ratio respectively, assume $\sigma_{\text {max }}=\sigma_{w, z d}=70 M P a$, considering the actual case of housing during operation process will undergo tension and compression load, so $R=-1$, and at this time $\sigma_{a}=\sigma_{\max }$, the calculation method of stress ratio $R$ is defined by the Equation (6):

$$
R=\frac{\sigma_{m}-\sigma_{a}}{\sigma_{m}+\sigma_{a}}
$$

In Equation (6): $\sigma_{m}$ - average stress; $\sigma_{a}$-stress amplitude;

Take parameters of Equation 6 into Equation 5, we found out the $N_{f} \approx 1.04 \times 10^{6}$ loading cycles. It is easy to see that in Equation (5), the two key parameters affecting crack propagation life 
are equivalent aperture diameter $L_{0}$ and load stress amplitude $\sigma_{a}$. Therefore, in order to achieve expected fatigue life, we need prescribe the allowable stress $\sigma_{a}$ which corresponding to $L_{0}$.

\section{Correction Algorithm of Fatigue Evaluation}

According to the fatigue regulations of casting aluminum alloy material in FKM-2012 guideline and DIN EN-1706 standard, the fatigue strength of $\mathrm{AlSi}_{7} \mathrm{Mg}_{0.3}$ as follow Table $2^{[11][12]}$.

Table2. Fatigue strength of $\mathrm{AlSi}_{7} \mathrm{Mg}_{0.3}$ material

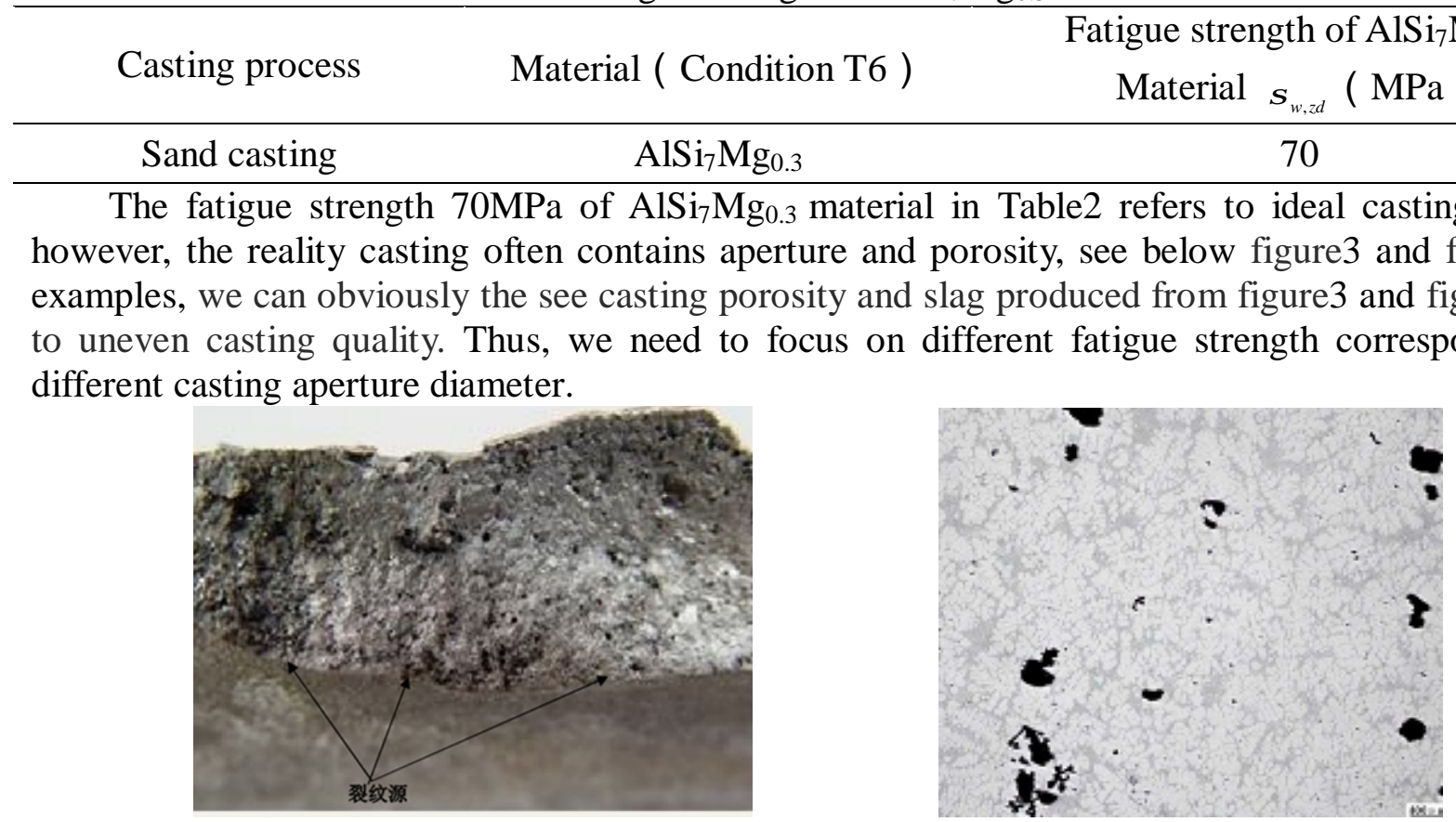

Fig3. Appearance in the fracture area Fig4. metallographic structure in the fracture area

In fact, the EN1999-1-3 standard for casting aluminum alloy aperture grades explained the relationship between casting aperture and fatigue strength, see Table $3^{[13]}$, but the fatigue strength corresponding to $N_{D}=1 \times 10^{7}$ cycles is not be clearly defined, which is focus of research in this article.

Table3. Fatigue strength of $\mathrm{AlSi}_{7} \mathrm{Mg}_{0.3}$ corresponding to different casting aperture diameter base on EN1999-1-3 [Mpa]

\begin{tabular}{cccccc}
\hline \multirow{2}{*}{ Detail Category } & \multicolumn{5}{c}{ Casting Aperture (mm ) } \\
\cline { 2 - 6 } & $0.2 \mathrm{~mm}$ & $0.5 \mathrm{~mm}$ & $0.9 \mathrm{~mm}$ & $1.5 \mathrm{~mm}$ & $2.0 \mathrm{~mm}$ \\
\hline$N_{D}=2 \times 10^{6}$ & 71 & 50 & 40 & 32 & 25 \\
\hline$N_{L}=1 \times 10^{8}$ & 40.6 & 28.6 & 22.9 & 18.3 & 14.3 \\
\hline
\end{tabular}

According to FKM guideline, the minimum safety factor $\left(J_{D}\right)$ calculation method is defined by the Equation (7):

$$
J_{D i, j}=j_{s} \cdot \frac{j_{F i} \cdot j_{G j}}{k_{T, D}}
$$

In Equation (7):

$j_{s}=1.0$, loading safety coefficient (recommended value for safety design);

$j_{F i}=1.5 \sim 1.3$, material safety coefficient (recommended value refer to table $3, i=1 \sim 5$ );

$j_{G j}=1.0 \sim 1.4$, casting coefficient (recommended value refer to table $3, j=1 \sim 5$ );

$k_{T, D}=(1 \sim 1.2) \times 10^{-3}\left(T /{ }^{0} \mathrm{C}-50\right) \quad\left(\right.$ Recommended temperature coefficient, this article set $\left.k_{T, D}=1\right)$; 
For the $j_{G i}$ and $j_{F j}$, this article references EN1999-1-3 standard for casting aluminum alloy porosity grades classification, as Table 4 .

Table4. Coefficients Corresponding to Different Casting Aperture Diameter Base on FKM $\left(1 \times 10^{7}\right.$ cycles $)$

\begin{tabular}{|c|c|c|c|c|c|}
\hline Casting Aperture (mm ) & 0.2 & 0.5 & 0.9 & 1.5 & 2.0 \\
\hline Casting Coefficient $j_{G i}$ & $j_{G 1}$ & $j_{G 2}$ & $j_{G 3}$ & $j_{G 4}$ & $j_{G 5}$ \\
\hline material safety coefficient $j_{F j}$ & $j_{F 1}$ & $j_{F 2}$ & $j_{F 3}$ & $j_{F 4}$ & $j_{F 5}$ \\
\hline
\end{tabular}

Set $j_{G 1}=1.0, j_{F 1}=1.3, j_{G 5}=1.4, j_{F 5}=1.5$, according to Equation (7), the $J_{D 1,1}=1.3$ and $J_{D 5,5}=2.1$. Reference the stress calculation methods of FKM corresponding to different loading cycles as figure 5 , the fatigue strength $\Delta \sigma_{i}$ of $\mathrm{AlSi}_{7} \mathrm{Mg}_{0.3}$ can be calculated by Equation (8).

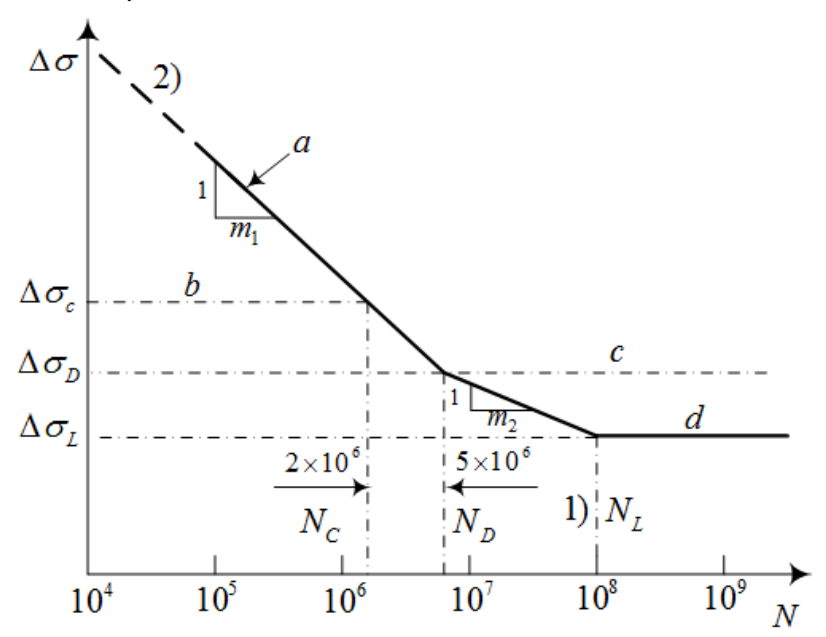

Fig5. Fatigue strength curve of casting of aluminum alloy

Notes: a-fatigue strength curve; $b$ - reference fatigue strength; $c$ - constant amplitude fatigue limit; $d$ - cut off limit; $\Delta \sigma-n o m i n a l$ stress range; $\Delta \sigma_{c}$-the stress of $N_{C}$ times load cycles; $\Delta \sigma_{D}$-constant amplitude stress; $\Delta \sigma_{L}-$ cut off limit stress; $N_{C}-2 \times 10^{6}$ times load cycles; $N_{D}-5 \times 10^{6}$ times load cycles; $N_{L}-10^{8}$ times load cycles.

In above figure 5, when the fatigue load cycles $N_{i}$ in the range between $5 \times 10^{6}$ to $1 \times 10^{8}$ cycles, the fatigue strength calculate method is defined by the Equation (8):

$$
\Delta \sigma_{i}=\frac{\Delta \sigma_{c}}{\sqrt[m 2]{\frac{N_{i}}{5 \times 10^{6}}} \cdot \sqrt[m 1]{\frac{5}{2}} \cdot \gamma_{F f} \cdot \gamma_{M f}}
$$

In Equation(8) :

$N_{i}$-The predicted number of cycles of failure of a stress range $\Delta \sigma_{i}$ (The target cycles

$$
N_{i}=1 \times 10^{7} \text { ); }
$$

$\Delta \sigma_{c}$-Fatigue strength of material $\left(\Delta \sigma_{c}=70 M P a\right)$;

$\Delta \sigma_{i}$-The fatigue strength under $N_{i}$ load cycles;

$\gamma_{F f}$-The density coefficient of fatigue load (in this article, recommended value is $\gamma_{F f}=1.0$ );

$\gamma_{M f}$-Fatigue strength coefficient (In this article, recommended value is $\gamma_{M f}=1.0$ );

$m_{1}$ - The inverse slope of $\Delta \sigma-N$ curve (In this article recommended value is $m_{1}=7$ );

$m_{2}$-The inverse slope of $\Delta \sigma-N$ curve (In this article recommended value is $m_{2}=m_{1}+2$ );

So the $\Delta \sigma_{i}$ is defined by the Equation (9): 


$$
\Delta \sigma_{i}=\frac{70 \times \sqrt[7]{\frac{2}{5}}}{\sqrt[9]{2}}=56.84(\mathrm{MPa})
$$

According to Table4, this article revised calculation method of fatigue strength ,as follow Equation (10):

$$
\Delta \sigma_{i}^{*}=\frac{\Delta \sigma_{i}}{J_{D i, j}}
$$

Consequently, $\Delta \sigma_{1}{ }^{*}=43.72 \mathrm{MPa}, \Delta \sigma_{5}{ }^{*}=27.07 \mathrm{MPa}$.

Other reference values of $\mathrm{AlSi}_{7} \mathrm{Mg}_{0.3}$ fatigue strength corresponding to different casting aperture diameter showing in Table3.

In figure6, it is easily to find out that when the diameter of casting aperture reach to $2.0 \mathrm{~mm}$, the fatigue strength $\left(1 \times 10^{7}\right)$ is $\Delta \sigma_{5}{ }^{*}=27.07 \mathrm{MPa}$, which more than the fatigue strength corresponding to $1 \times 10^{8}$ cycles, obviously, this result is unreasonable for fatigue strength evaluation of $\mathrm{AlSi}_{7} \mathrm{Mg}_{0.3}$. Thus, we should adjust $j_{G i}$ or $j_{F j}$ to meet $\Delta \sigma_{i}^{*}$ between curve $2 \times 10^{6}$ and curve $1 \times 10^{8}$.

This article suggest $j_{F i}=1.7 \sim 1.3$ as well as reallocate the parameters as follow Table5:

Table5. Revised Coefficients Corresponding to Different Casting Aperture Diameter $\left(1 \times 10^{7}\right)$

\begin{tabular}{cccccc}
\hline Casting Aperture $(\mathrm{mm})$ & 0.2 & 0.5 & 0.9 & 1.5 & 2.0 \\
\hline Casting Coefficient $j_{G i}$ & 1.3 & 1.35 & 1.5 & 1.6 & 1.7 \\
\hline material safety coefficient $j_{F j}$ & 1.0 & 1.1 & 1.2 & 1.3 & 1.4 \\
\hline
\end{tabular}

As result, the fatigue curve $\left(1 \times 10^{7}\right)$ with revised coefficients as follow figure7, which is a reasonable result between curve $2 \times 10^{6}$ and curve $1 \times 10^{8}$.
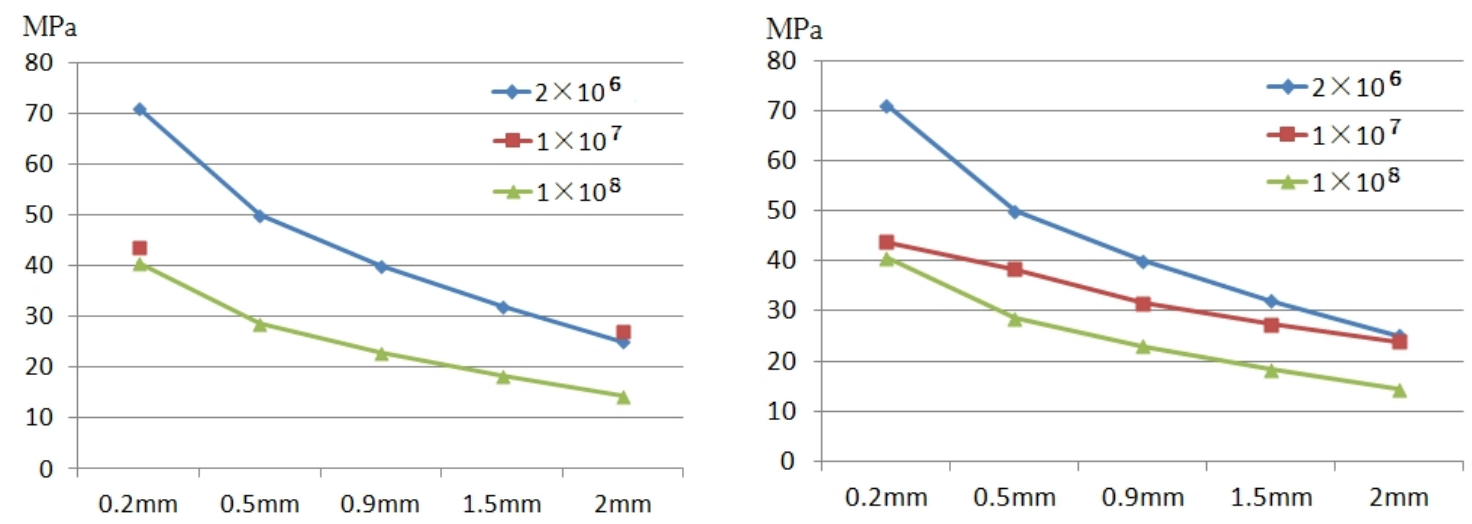

Fig6. Fatigue strength curve of $\mathrm{AlSi}_{7} \mathrm{Mg}_{0.3}$ Fig7. The revised fatigue strength curve of $\mathrm{AlSi}_{7} \mathrm{Mg}_{0.3}$

This article corrected fatigue assessment values of $\mathrm{AlSi}_{7} \mathrm{Mg}_{0.3}$ casting aluminum alloy, the recommended values for various conditions can be seen in Table6. Considering the minimum safety coefficient should be more than 1.0 for actual product, the special values should be determined according to loading conditions corresponding to different structural positions.

\begin{tabular}{|c|c|c|c|c|}
\hline \multirow{2}{*}{$\begin{array}{l}\text { Casting } \\
\text { process }\end{array}$} & \multirow{2}{*}{$\begin{array}{c}\text { Material } \\
\text { ( Condition T6 ) }\end{array}$} & \multirow{2}{*}{$\begin{array}{c}\text { Fatigue strength of } \\
\mathrm{AlSi}_{7} \mathrm{Mg}_{0.3} \text { Material } \\
\sigma_{w, z d}(\mathrm{MPa})\end{array}$} & \multirow{2}{*}{$\begin{array}{c}\text { Casting aperture } \\
(\mathrm{mm})\end{array}$} & $\begin{array}{l}\text { The corrected fatigue } \\
\text { strength } \Delta \sigma_{i}^{*}(\mathrm{MPa})\end{array}$ \\
\hline & & & & $1 \times 10^{7}$ \\
\hline \multirow{5}{*}{ Sand castings } & \multirow{5}{*}{$\mathrm{AlSi}_{7} \mathrm{Mg}_{0.3}$} & \multirow{5}{*}{70} & 0.2 & 43.72 \\
\hline & & & 0.5 & 38.28 \\
\hline & & & 0.9 & 31.58 \\
\hline & & & 1.5 & 27.33 \\
\hline & & & 2.0 & 23.88 \\
\hline
\end{tabular}

Table6. Recommended values for evaluation of $\mathrm{AlSi}_{7} \mathrm{Mg}_{0.3}$ fatigue strength 


\section{Testing verification}

In order to verify the revised values of fatigue evaluation for $\mathrm{AlSi}_{7} \mathrm{Mg}_{0.3}$, we selected a new housing product from the same structure products, the same technique and the same batch to equip strain gauge in the corresponding crack location ${ }^{[14]}$, we demand the maximum casting aperture diameter(more than $0.5 \mathrm{~mm}$ ) is not be allowed, besides that, we did vibration simulation test on the test bench, the test conditions simulated actual operation condition between two railway stations, the test case as below figure8.

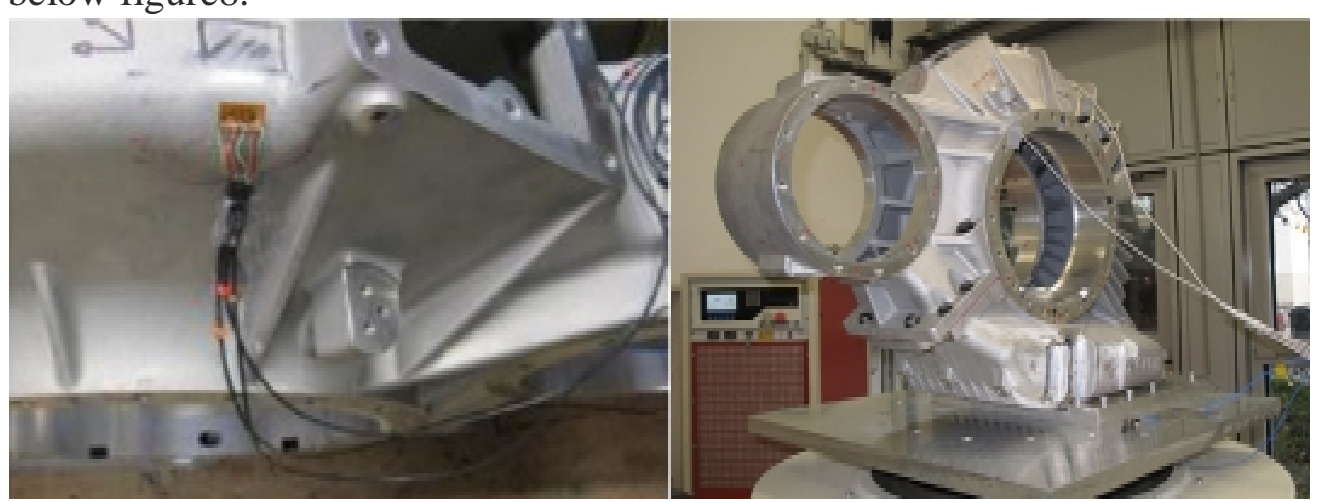

Fig8. Dynamic stress experiment for housing crack location

Under the vibration condition, the dynamic stress measurement points will be affected by load of tension and compression, the test data is shown in figure9, in which stress data more than $\pm 38.28 \mathrm{MPa}$ are shown by oval-ring note.

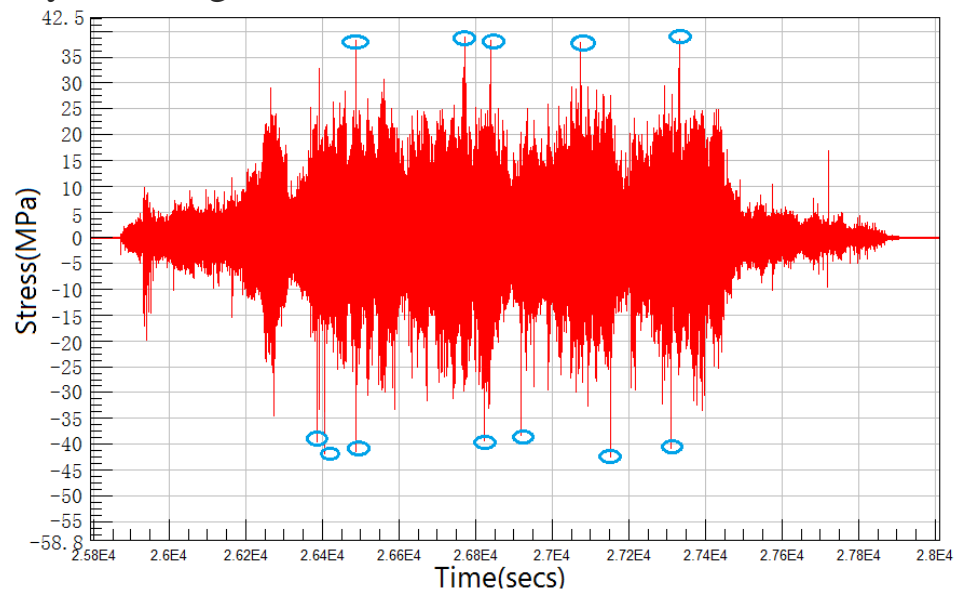

Fig9. Data of dynamic stress experiment

Reference the table 6 and figure9, it is not difficult to understand that if the casting aperture diameter bigger than $0.5 \mathrm{~mm}$ in crack position the fatigue fracture can be caused by vibration load easily when stress reach to $38.28 \mathrm{MPa}$ and above. In addition, we selected five new housing products to extract five pieces of samples, which in corresponding to crack position, as well as we did bending fatigue test on the fatigue test bench, the test method as figure 10.
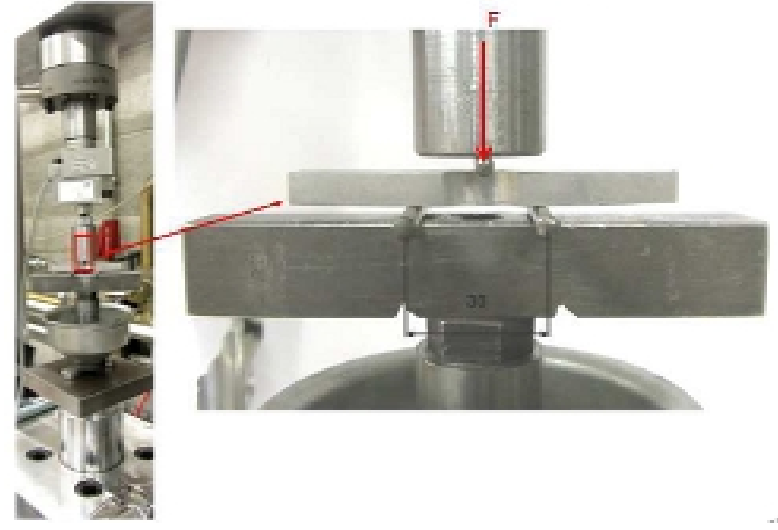

Fig10. Fatigue test of simples for $\mathrm{AlSi}_{7} \mathrm{Mg}_{0.3}$ housing 
Based on test results, the S-N curve scatter diagram of test results from extracted five pieces samples as shown in figure 11, the red curve represents FKM specified curve of $\mathrm{AlSi}_{7} \mathrm{Mg}_{0.3}$, when the fatigue loading cycles reached to $1 \times 10^{7}$ cycles, there are two pieces of samples stress lower than 38.28MPa.

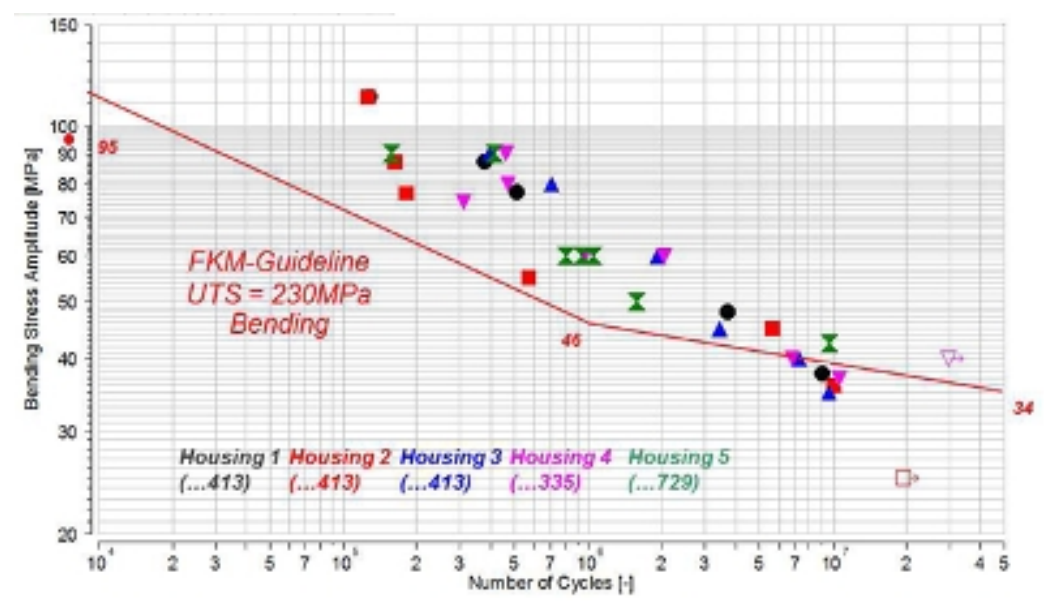

Fig11. Fatigue curve of samples

In above figure 11 , stress amplitude corresponding to the approximate $1 \times 10^{7}$ load cycles has been summarized into Table7.

Table7. Stress amplitude corresponding to $10^{7}$ load cycles

\begin{tabular}{ccc}
\hline Samples & Signs & Stress Amplitude (MPa) \\
\hline Housing1 & $\bullet$ & 38.9 \\
\hline Housing2 & $\boldsymbol{\Delta}$ & 36.4 \\
\hline Housing3 & $\boldsymbol{\nabla}$ & 35.0 \\
\hline Housing4 & $\mathbf{\Sigma}$ & 38.5 \\
\hline Housing5 & & 44.6
\end{tabular}

\section{Conclusions}

Since the casting process of aluminum alloy can not avoid porosity, shrinkage or slag completely, casting quality has a obvious effects on fatigue life, thus, it often leads to a big difference between theory life and real life for same batch casting housings. In this article, according to the crack characteristics of $\mathrm{AlSi}_{7} \mathrm{Mg}_{0.3}$ housings, the crack propagation prediction algorithm is deduced based on $\mathrm{AlSi}_{7} \mathrm{Mg}_{0.3}$ casting aluminum alloy properties, a calculation example is given based on the revised parameters, as well as the key determinants of crack propagation parameters is deduced. In order to verify the accuracy of the recommended values in this article, the dynamic stress of housing has been test on test bench, and samples fatigue test has been done. As one example, the test results show that if casting aperture diameter more than $0.5 \mathrm{~mm}$, the stress amplitude of fatigue load should not be more than $38.28 \mathrm{MPa}$ for $1 \times 10^{7}$ load cycles.

\section{Acknowledgements}

This work was financially supported by the National Key Technology Development Plan-Key

Technology Research on Gauge Changeable High-speed Train ( 2016YFB1200501 ) .

\section{References}

[1] Vencl, Bobic, Miskovic. Effect of thixocasting and heat treatment on the tribological properties of hypoeutectic Al-Si alloy[J]. WEAR, 2007, Vol(264):616-623. 
[2] Birol Yucel. Impact of grain size on mechanical properties of AlSi7Mg0.3 alloy[J]. MATERIALS SCIENCE AND ENGINEERING A-STRUCTURAL MATERIALS PROPERTIES MICROSTRUCTURE AND PROCESSING, 2012, Vol(559): 394-400.

[3] Terek Pal , Kovacevic Lazar, Miletic Aleksandar,.etc. Effects of die core treatments and surface finishes on the sticking and galling tendency of Al-Si alloy casting during ejection[J]. WEAR, 2016, Vol(356-357): 122-134.

[4] Hashemi , Hussain. Wear performance of Al/TiN dispersion strengthened surface composite produced through friction stir process: A comparison of tool geometries and number of passes[J]. WEAR, 2016, Vol(324): 45-54.

[5] Krupp, Giertler, Siegfan,.ect. Mutual Interaction between Fatigue Crack Initiation/Propagation and Micro-structural Features in Cast Aluminum Alloys[C]. 11th International Fatigue Congress, 2014, Vol(891-892): 488-493.

[6] E Alexandre , S . Deyber, A.Pinean , Modelling the optimum grain size on the low cycle fatigue life of a Ni based superalloy in the presence of two possible crack initiation sites[J]. Scripta Mater, 2004,50(1)25-30.

[7] Mishnaevsky, Lippmann, Schmauder,.ect. In-situ observation of damage evolution and fracture in AlSi7Mg0.3 cast alloys[J]. ENGINEERING FRACTURE MECHANICS, 1999, Vol(63): 395-411.

[8] Schueler Paul, Frank Robert, Uebel David,.ect. Influence of heat treatments on the microstructure and mechanical behavior of open cellAlSi7Mg0.3 foams on different length scales[J]. ACTA MATERIALIA. 2016, Vol(109):32-45.

[9] M . J . Caton, J . W Jones, LE . Allison . The effect of solidification rate on the growth of small fatigue cracks in a cast 319-type aluminum alloy[J] . Metallurgical and Materials Transactions A,1999, Vol 30(12) : 3055-3068.

[10] JZ Yi . YX Gao . PD Lee, HM Flower, TC Lindley, Scaller in fatigue life due to effects of porosity in Cast A356-T6 aluminum-silicon alloys[J]. Metallurgical and Materials Transactions A . 2003 . Vol(34A) : 1879 1 891.

[11] Forschungskuratorium Maschinenbau(FKM).Analytical strength assessment of components in mechanical engineering[S].2012.

[12] GINA. Aluminum and aluminum alloys Castings Chemical composition and mechanical properties[S].2010.

[13] CEN. Design of aluminum structures-Part 1-3:Structures susceptible to fatigue[S].2006.

[14] Mayer, Lipowsky, Lipowsky,.ect. Application of ultrasound for fatigue testing of lightweight alloys[J]. FATIGUE \& FRACTURE OF ENGINEERING MATERIALS \& STRUCTURES, 1999, $\operatorname{Vol}(22): 591-599$.

\section{Author}

LI Guodong(1975-),Male, ChangLing City of JI Lin Province, Ph.D , Professorate Senior Engineer.

E-mail : maklcewxy@163.com,TEL:(+0086)15948068596 
